\title{
Nano-Silica Modified by Hematoporphyrin for Determination Some of Traces Metals Ions (Cu(II), Zn(II) and Mn(II)) in Environmental and Pharmaceutical Formula
}

\author{
Esam Bakeir ${ }^{1,2^{*}}$, Salma Attaf ${ }^{1}$ and Mohamed El-shahat ${ }^{1}$ \\ ${ }^{1}$ Department of Chemistry, Faculty of Science, Ain Shams University, Cairo, Egypt \\ ${ }^{2}$ Department of Chemistry, College of Science, King Faisal University, Hofuf, Saudi Arabia
}

\begin{abstract}
Recovering of heavy metal ions $\mathrm{Zn}(\mathrm{II}), \mathrm{Cu}(\mathrm{II})$ and $\mathrm{Mn}(\mathrm{II})$ in aqueous solution has been investigated using a novel nano silica modified by hemtaprophyrin. Nano sorbent was prepared by sol gel method. Transmission electron microscope and EDAX analysis showed the nano scale with porosity of a new sorbent. The proposed structure of modified silica with HP was predicted according to FTIR and elemental analysis. The new sorbent have good thermal stability. The phenomena of the sorbent sorption included the static studies such as $\mathrm{pH}$ and the Langmuir and Freundlish models were applied at equilibrium state. The linear regression analysis was Langmuir isotherm according to the values of relation coefficient $\left(R^{2}\right)$. The limit of detection (LOD) for $\mathrm{Zn}, \mathrm{Cu}$ and $\mathrm{Mn}$ were $0.01,0.12$ and $0.03 \mu \mathrm{g} \mathrm{L}^{-1}$ respectively, within the analytical range $0.1-10 \mathrm{\mu gL}^{-1}$. This method achieved highly precision for the samples of environmental and pharmaceutical formulations of $\%$ RSD less than $10 \%$.
\end{abstract}

Keywords: Nano-Sorbent; Langmuir isotherm; Limit of detection; Pharmaceutical formulation

\section{Introduction}

Toxicity of heavy metal ions such as copper, Lead and zinc consider a big environmental pollution problem where there are many sources of this metal ions like soils, industrial wastes and geological samples [1] Flame and graphite furnace absorption spectrometry techniques used for determination concentration of this metal ions at low concentration directly [2]. Low cost and efficiency of the use of solid phase extraction technology have become more common for the analysis of the components of samples in high and low concentrations. This technique can be automatically controlled and used in the pharmaceutical, environmental research and food industries [3]. The disadvantage of some analytical techniques for example flame or graphite furnace atomic spectroscopy, inductively coupled plasma atomic emission spectroscopy(ICP-AES) and Inductively Coupled Plasma-Mass Spectroscopy (ICP-MS) for determination trace metal ions such as copper, zinc and nickel are less sensitivity for this metal ions with matrix interference so solving these problem, the preconcentration and separation techniques are used to maintain the limit of detection within the range of the proposed method. The development of the preconcentration and separation techniques is necessary [4-6]. The most common of preconcentration methods is solid phase extraction(SPE) have several advantages over other methods [7-9] such as coprecipitation [10] ion exchange [11], solvent extraction [12]. The efficiency of water treatment with removal trace metal ions from drinking, ground and wastewater carried out with selective preconcentration and separation processes [13]. Functionalized sorbents have Features such as i) highly selectivity to targeted metal ion, ii) Overcome the difficulty of phase separation of the solubility between water and organic solvent iii) Determination the metal ions within part per billion concentrations, Iv) The adsorption of metal ions is visual for color complexes [14]. The development of SPE materials for determination heavy metal ions incorporation inorganic or organic materials in matrices such as modified silica [15], cellulose [7], Amberlite XAD-4 modified with nano-manganese dioxide [16] activated carbon [17] polyurethane foam [18] and multiwall carbon nanotubes (MWCNTs) [19].
The most efficient sorbent for solid phase extraction (SPE) is modified silica gel incorporated with chelating organic ligand or inorganic compound to removal of metal ions due to high porosity, hydrophilicity and ease of surface modification. There are physically and chemically modified on the surface of silica gel using chelating organic ligand. The modification of silica gel surface using organic chelating agent increased the selectivity and sensitivity of SPE towards metal ions. Increasing the selectivity of silica sorbent by introduce donor atoms $(\mathrm{O}$, $\mathrm{N}, \mathrm{P}$ and $\mathrm{S}$ ) of immobilized organic matter along the surface of silica and form a stable complex with uptake of the desired metal ions [20]. there are many chelating ligands immobilized introduce on silica surface such as Silica gel functionalized with 1,8-dihydroxyanthraquinone [21], 2 -aminomethylpyridine [22], p-dimethylaminobenzaldehyde, [23] have been used to enrich for metal ions.

The aim of this article, preparation modified silica with hematoporphyrin sorbent using sol gel method. FTIR, elemental analysis, thermal gravimetric analysis, transmission electron microscope and EDX techniques were studied the chemical structure, size diameter and thermal stability of desired sorbent. The adsorption parameters of determination of metal ion $\mathrm{Zn}(\mathrm{II}), \mathrm{Cu}(\mathrm{II})$ and $\mathrm{Mn}$ (II) using a nano sorbent have been studied at different $\mathrm{pHs}$, with various shaking time, flow rate, type of eluent and interference of ions. Langmuir and freundlich isotherm models have been tested for the adsorption equilibrium of maximum adsorbed metal ions and kinetic analysis was examined the order of the reaction. The analytical validation (precision, accuracy and Limit of detection LOD) of this method was examined for water and pharmaceutical samples.

*Corresponding author: Esam Bakeir, Department of Chemistry, College of Science, King Faisal University, Hofuf, Saudi Arabia, Tel: 00966509725364; E-mail: Esambakir99@yahoo.com

Received July 15, 2017; Accepted July 22, 2017; Published July 27, 2017

Citation: Bakeir E, Attaf S, El-shahat M (2017) Nano-Silica Modified by Hematoporphyrin for Determination Some of Traces Metals lons (Cu(II), Zn(II) and $\mathrm{Mn}(\mathrm{II}))$ in Environmental and Pharmaceutical Formula. J Environ Anal Toxicol 7: 495. doi: 10.4172/2161-0525.1000495

Copyright: @ 2017 Bakeir E, et al. This is an open-access article distributed under the terms of the Creative Commons Attribution License, which permits unrestricted use, distribution, and reproduction in any medium, provided the original author and source are credited. 
Citation: Bakeir E, Attaf S, El-shahat M (2017) Nano-Silica Modified by Hematoporphyrin for Determination Some of Traces Metals lons (Cu(II), Zn(II) and $\mathrm{Mn}(\mathrm{II}))$ in Environmental and Pharmaceutical Formula. J Environ Anal Toxicol 7: 495. doi: 10.4172/2161-0525.1000495

Page 2 of 9

\section{Experimental}

All solvents and reagents were highly analytical grade without purification such as Copper sulphate pentahydrate, Zinc sulfate heptahydrate, manganese sulfate pentahydrate and tetraethoxysilane purchased from Sigma-Aldrich. All glassware remained overnight in $10 \%(\mathrm{v} / \mathrm{v}) \mathrm{HNO}_{3}$ then washed several times with double-distilled water. A standard stock solution $\left(100 \mathrm{mg} \mathrm{L}^{-1}\right)$ of zinc, copper and nickel was prepared by dissolving the respective metal salts, and the working solutions were prepared by appropriate dilution with double-distilled water. Series of stock solutions of metal ions were used for plotting the calibration curve of the range $0-10.0 \mu \mathrm{g} \mathrm{L}^{-1}$. Dilute Hydrochloric acid and sodium hydroxide were used to adjust the $\mathrm{pH}$ of the samples. There are three types of the extracted samples were used in adsorption process.

\section{Olives samples}

The samples were received from local market(Egypt), Cleaning, cutting then drying olive leaves in oven for $10 \mathrm{~h}$ at $80^{\circ} \mathrm{C}$. Take $0.50 \mathrm{~g}$ of dried sample dissolve in concentrated $\mathrm{HNO}_{3}$ and it dryness. The residue dissolved by double distilled water and neutralized with $\mathrm{NaOH}$. The solution transferred into $50 \mathrm{ml}$ measuring flask and filled with Distilled water.

\section{Fish liver}

The samples were received from local market (Egypt). Cleaning, cutting then drying the sample in an oven at $105^{\circ} \mathrm{C}$ for $24 \mathrm{~h}$. Dry sample was ignited into a clean dried porcelain crucible for $2 \mathrm{~h}$ at $200^{\circ} \mathrm{C}$ gradually to $600^{\circ} \mathrm{C}$ in a muffle furnace. An accurate weighed $0.4 \mathrm{~g}$ of the final sample digested in $\mathrm{HNO}_{3}$ till nearly dryness. The residue dissolved by double distilled water and neutralized with $\mathrm{NaOH}$. The solution transferred into $50 \mathrm{ml}$ measuring flask and filled with Distilled water.

\section{Tap water}

The samples were collected from sewage (chemistry dept. College of science, Ain shams university, Egypt). The sample was filtered to remove the suspended particles and adjusted $\mathrm{pH}=6.5$ of samples by using 0.01 mol L-1 $\mathrm{HNO}_{3}$.

\section{Pharmaceutical sampling}

Pharmaceutical capsule of Kerovit was brought from Amoun Pharma Co (EGYPT). The sample of $1.768 \mathrm{~g}$ was dissolution into 20 $\mathrm{mL}$ of conc. $\mathrm{HNO}_{3}$ then neutralized with $\mathrm{NaOH}$ and diluted to obtain 1 liter of sample.

The adsorption process of the samples was tested with nano sorbent HP-Silica which it prepared by sol gel method. From the BET data of nano sorbent HP-Silica given the surface area, average pore volume and pore radius were $176.490 \mathrm{~m}^{2} / \mathrm{g}$ and $0.097 \mathrm{cc} / \mathrm{g}$ and $7.173 \mathrm{~nm}$ respectively.

\section{Procedure for adsorption experiment}

The adsorption behavior of copper, nickel, zinc, cadmium and lead metal ions were examined by both batch and column conditions. The operational variables were optimized through batch process. The batch method was used to determine the adsorption capacity. The elution of the adsorbed metal ions was done in the column process.

\section{Adsorbent preparation}

Modified nano silica with hematoporphyrin was prepared sol gel method [24], Add 0.01 molar of hematoporphyrin to the solution of tetra ethoxy silane (TEOS), ethanol, $\mathrm{H}_{2} \mathrm{O}$ and hydrochloric acid $(\mathrm{HCl})$ with molar ratio (1:2:4:0.01) respectively. The solution constantly stirring at room temperature for $1 \mathrm{~h}$. The solution became gel form with homogenous. Dried gel at $110^{\circ} \mathrm{C}$ in an electric oven for 3 days. After nano HP-Silica was dried, it was stored for future experimental studies.

Batch process: The uptake of metal ions was recorded for the sample volume $10 \mathrm{ml}$ with different concentration ranges $0.5-30 \mu \mathrm{g} \mathrm{L}^{-1}$ of $\mathrm{Zn}(\mathrm{II}), \mathrm{Cu}(\mathrm{II})$ and $\mathrm{Mn}(\mathrm{II})$. The $\mathrm{pH}$ of analyte was adjusted by adding $\mathrm{HCl}$ or $\mathrm{NaOH}$ solution. The optimized $\mathrm{pH}$ of samples transferred in a clean conical flask containing $0.1 \mathrm{~g}$ of nano HP-Silica. The shaking time of solution was $1 \mathrm{~h}$ then filtered the solution using Whatman 41 . The concentration of the filtrate solution was measured at flame atomic absorption spectroscopy (FAAS). The adsorption values of metal ions ( $\mathrm{Zn}(\mathrm{II}), \mathrm{Cu}(\mathrm{II})$ and $\mathrm{Mn}(\mathrm{II})$ ) was estimated by the eq (1):

$$
q_{e}=\left(\frac{C_{0}-C_{e}}{m}\right) V
$$

where $\mathrm{C}_{0}$ and $\mathrm{C}_{e}$ initial and equilibrium metal ions concentration $\left(\mu \mathrm{g} \mathrm{L}^{-1}\right)$ respectively, $\mathrm{V}(\mathrm{mL})$ is the volume of metal ions and $\mathrm{m}(\mathrm{g})$ is the weight of nno sorbent.

The removal percentage of metal ions (\%) was estimated by eq (2):

$$
\% \operatorname{Re} \text { moval }=\frac{\left(C_{0}-C_{e}\right)}{C_{0}} * 100
$$

In batch process, there are several parameters were studied on the adsorption capacity of adsorbent such as $\mathrm{pHs}$, adsorbate concentration, shaking time, eluent nature and its concentration.

Column preparation: In the column experiments, $0.1 \mathrm{~g}$ of nano HP silica was packed in a thin syringe. The solutions of metal ions was adjusted to a proper $\mathrm{pH}$ and percolated with a certain flow rate vacuum pump. The adsorbed eluted with an appropriate eluent $\left(0.1 \mathrm{~mol} . \mathrm{L}^{-1}\right.$ $\mathrm{HNO}_{3}$ ) then determined their concentrations.

The column method: The sample $(5 \mathrm{~mL}$ sample volume with concentration $0.5 \mu \mathrm{g} \mathrm{L}^{-1}$ ) of metal ions was passed through the column and $\mathrm{pH}$ adjusted precondition passed the solution on glass column (3 $\mathrm{cm}$ long and $1.0 \mathrm{~cm}$ in diameter) was packed with $0.1 \mathrm{~g}$ of nano HPsilica beds help of silica wool at bottom. The flow rate was performed to the desired value determined experimentally $\left(0.254 .0 \mathrm{~mL} \mathrm{~min}{ }^{-1}\right)$. The adsorbed metal ions were recovered by passing $0.1 \mathrm{~mol} \mathrm{~L}^{-1} \mathrm{HNO}_{3}$. The column washed many times with double distilled water. The adsorption and $\%$ removal of trace metal ions were estimated from the difference between the initial concentration of metal ions $\mathrm{C}_{0}$ and the recovery concentration Ce according to Eq. (1) and (2). The flow rate and sample volume were optimized and tested in column.

\section{Instrumentation}

The IR spectrum of samples was recorded using a Perkin Elmer (USA) FT-IR Nicolet 6700 spectrophotometer. Thermal gravimetric analysis measured by TGA-50H (RASHA) analyzing. BET data were measured on NOVA-station. The adsorption concentration of metal ions were performed with FAAS (SOLAAR 3 Help@969 MKI) was used to determine the concentration of extracting metal ions. All $\mathrm{pH}$ measurements were measured with WTW $\mathrm{pH}$ meter. Scanning electron microscope (SEM) images were obtained from JEOL/ EQ JSM Instruments 1200 (Japan). Automatic analyzer CHNS, Elementar vario EL(III), Germany used to elemental analysis. 
Citation: Bakeir E, Attaf S, El-shahat M (2017) Nano-Silica Modified by Hematoporphyrin for Determination Some of Traces Metals lons (Cu(II), Zn(II) and $\mathrm{Mn}(\mathrm{II})$ ) in Environmental and Pharmaceutical Formula. J Environ Anal Toxicol 7: 495. doi: 10.4172/2161-0525.1000495

Page 3 of 9

\section{Results and Discussion}

\section{Characterization of nano HP-silica}

Figure 1, show the spectra of a) pure TEOS have a wide band around at $3284 \mathrm{~cm}^{-1}$ refers to stretching vibration of $\mathrm{O}-\mathrm{H}$ group of each $\mathrm{Si}-\mathrm{OH}$ and $\mathrm{H}-\mathrm{OH}$ bonding. A weaker $\mathrm{O}-\mathrm{H}$ bending vibration band is recorded at $1653 \mathrm{~cm}^{-1}$. The bands located at 465 and $1087 \mathrm{~cm}^{-1}$ for stretching vibration of Si-O-Si group The band's position at 1272, 1496 and 953 $\mathrm{cm}^{-1}$ are refer to the $-\mathrm{CH}_{3}$ of the grafting of $-\mathrm{Si}-\left(\mathrm{CH}_{3}\right)_{3}$ groups attaching on the silica backbone, So the $\left(\mathrm{CH}_{3}\right)$ hydrophobic group attached to the silica backbone [25]. The IR spectrum of HP incorporated in silica matrix, most of silica bands were observed with small shift and the stretching vibration band of $(\mathrm{N}-\mathrm{H})$ for hematoporphyrin was appeared at $2787 \mathrm{~cm}^{-1}$ [26] so the proposed mechanism of the reaction between HP and silica matrix is hydroxyl and carboxylic groups of hematoporphyrin attached to $\mathrm{Si}-\mathrm{OH}$ of silica matrix.

Form Table 1 shown the $\%$ contents of $\% \mathrm{C}$ and $\% \mathrm{H}$ for HP-silica were higher than silica and also the $\% \mathrm{~N}$ was observed in new adsorbent nano HP-silica, this indicated to introduce HP on the surface backboned of silica.

Thermogravimetric analysis (TGA) was measured from 30 to $600^{\circ} \mathrm{C}$ for each silica and nano HP-silica sorbent. In Figure 2, the TGA curves shown a $15 \%$ and $5 \%$ weight loss ending up at $30-75^{\circ} \mathrm{C}$ for silica and HP-silica respectively, which is assigned to the adsorbed solvents $\left(\mathrm{H}_{2} \mathrm{O}\right.$, $\mathrm{EtOH}$ ) from the condensation of silica network. And the 5\% weight loss from $100-600^{\circ} \mathrm{C}$ is attributed to the pyrolysis of residual organics. The TG curve of the silica was observed no weight loss up to $300^{\circ} \mathrm{C}$ but

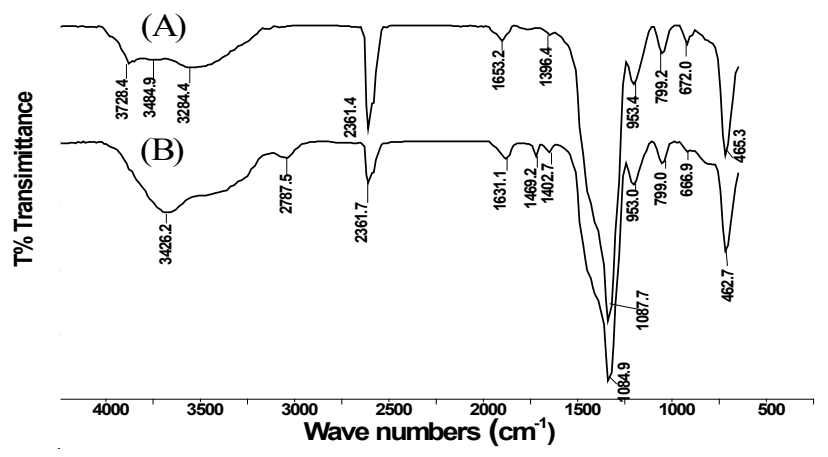

Figure 1: FTIR spectra of nano-Silica(A) and nano-HP silica (B).

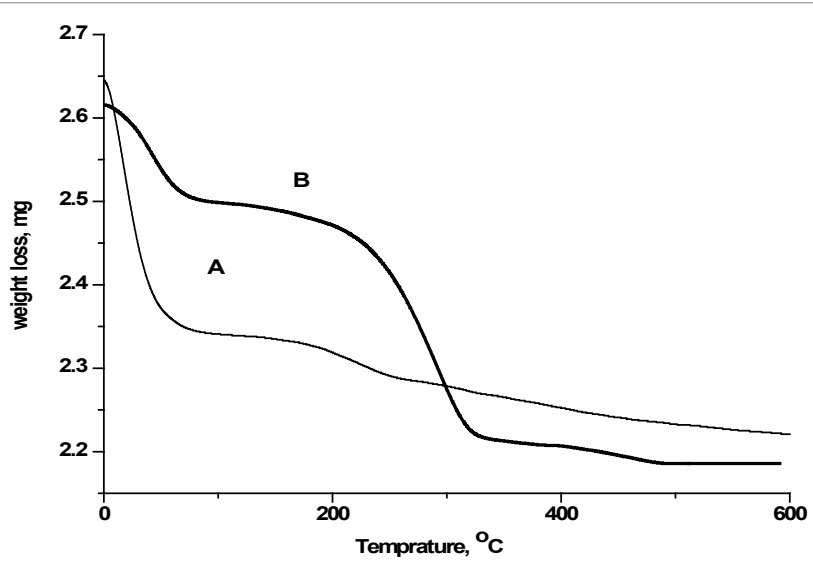

Figure 2: TGA curves of (A)nano-Silica and (B) nano-HP Silica. for nano sorbent have weight loss $250-325^{\circ} \mathrm{C}$ expected decomposition of organic moiety of hematoporphyrin and without loss of weight to $500^{\circ} \mathrm{C}$.

Morphological analysis (SEM) and compositional analysis (EDAX): SEM-EDX also used to detect the quantity of silicon ( $\mathrm{Si}$ ) and oxygen $(\mathrm{O})$ which are main composition of silica $\left(\mathrm{SiO}_{2}\right)$ and also detect the quantity of nitrogen $(\mathrm{N})$ in silica gel modified HP-silica. Scanning electron microscope was used to analysis the surface morphology of silica powder and nano HP-silica sorbent as represented in Figures 3 and 4 . The spherical and agglomerated silica nanoparticles shown the hematoporphyrin incorporated in the silica backbone with highly pore size. The EDAX analyses prove the successful synthesis of the silica material where Figure shows the $\mathrm{Si} / \mathrm{O}$ ratio composition of silica and nano sorbent $[27,28]$. TEM images show the size average of silica and nano sorbent was $8.0 \mathrm{~nm}$ and $7.4 \mathrm{~nm}$ respectively. The small size sorbent was made a high surface area and improved the extraction of metal ions from the solution [29].

BET analysis: Figure 5, shows the curve of adsorption-desorption isotherms of $\mathrm{N}_{2}$ gas at surface of HP-silica sorbent were tested. Type II observed of the isotherm behaviour. The sample has a surface area of $176.50 \mathrm{~m}^{2} / \mathrm{g}$, pore volume $0.097 \mathrm{~cm}^{3} / \mathrm{g}$ and pore radius $7.17 \mathrm{~nm}$. The non-porosity nature of the sample has a lower BET surface area [30].

\section{Batch method}

The adsorption capacity of metal ions depend on several variables for example chemical nature of each sorbent and adsorbate, $\mathrm{pHs}$ values, shaking time, eluent type and it is concentration were tested on silica modified by hematoporphyrin.

Influence of solution pH: Figure 6 shows the adsorption capacity of metal ions(adsorbate) gradually increasing on the surface of modified silica by hematoporphyrin from acidic to neutral medium then decreasing in basic medium. At low $\mathrm{pH}$, the surface of sorbent(HPsilica) was protonated with positive charge which it causing electrostatic repulsion with the metal ions (adsorbate) [31]. the adsorption capacity gradually increasing till neutral medium because the complex formation take place between the metal ions and chelating organic moiety hematoporphyrin at the surface of silica. At higher $\mathrm{pH}$, the metal ions were precipitated as $\mathrm{M}(\mathrm{OH})$ nor mixed charged hydroxide complexes. Precipitate made contamination on the surface of sorbent and hence a slight decline of the retention efficiency was achieved [32]. The optimized $\mathrm{pH}$ of best $\%$ of recovery of the metal ions at $\mathrm{pH}=6-7$.

\begin{tabular}{|c|c|c|c|}
\hline Materials & Content (\%) C & Content (\%) H & Content (\%) N \\
\hline Nano Silica & 1.09 & 1.24 & Nil \\
\hline Nano HP-silica & 5.29 & 8.82 & 1.26 \\
\hline
\end{tabular}

Table 1: Elemental analysis (C, $\mathrm{H}$ and $\mathrm{N})$ of nano silica and nano HP-Silica.
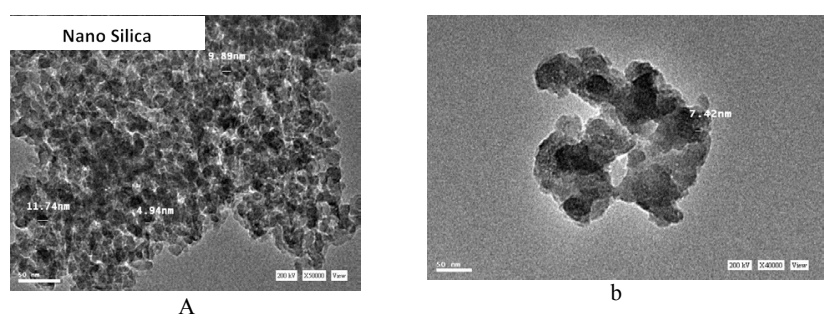

A

Figure 3: TEM images of the morphology of a) silica matrix and b) Nano-HP silica. 
Citation: Bakeir E, Attaf S, El-shahat M (2017) Nano-Silica Modified by Hematoporphyrin for Determination Some of Traces Metals lons (Cu(II), Zn(II) and $\mathrm{Mn}(\mathrm{II})$ ) in Environmental and Pharmaceutical Formula. J Environ Anal Toxicol 7: 495. doi: 10.4172/2161-0525.1000495

Page 4 of 9

\section{Adsorption kinetic models}

The minimum time period necessary to achieve maximum uptake of metal ions on the surface of modified silica by hematoporphyrin was tested the shaking time intervals $5,10,15,20,25$ and $30 \mathrm{~min}$. From Figure 7, The minimum time of maximum adsorption capacity was recorded for $\mathrm{Zn}$ (II) ion at time 20 min which it was less than the minimum time of maximum adsorption capacity of other metal ions. This indicated the fast sorption of diffusion of $\mathrm{Zn}$ (II) ion throughout a hypothetical or hydrodynamic boundary [33].

The kinetic mechanism controlling the adsorption of the metal ions was investigated by applying the pseudo first-order, pseudo-second order and intraparticle diffusion models to fit the experimental results.

The pseudo first order rate equation given by Lagergren and Kungliga [34] and supposed reaction between adsorbent and the adsorbate is monomolecular.

The linear equation plotted between $\log \left(\mathrm{q}_{\mathrm{e}}-\mathrm{q}_{\mathrm{t}}\right)$ vs time $t\left(\mathrm{~min}^{-1}\right)$ shown in equation 3.

$$
\log \left(q_{e}-q_{t}\right)=\log q_{e}-\frac{k 1}{2.303} * t
$$

where $\mathrm{q}_{\mathrm{e}}$ and $\mathrm{q}_{\mathrm{t}}$ are the sorbet metal ion $\left(\mu \mathrm{g} \mathrm{g}^{-1}\right)$ at equilibrium, $\mathrm{k}_{1}$ (rate constant $)=2.303^{\star}$ slope and time $t(\mathrm{~min})$, respectively.

The pseudo second order rate equation given by Ho [35] and supposed the reaction between the adsorbent and adsorbate is bimolecular. The linear relation given by equation 4

$$
\frac{t}{q_{e}}=\frac{1}{k_{2} q_{e}^{2}} * t
$$

A plot of $\mathrm{t} / \mathrm{q}_{\mathrm{t}}$ versus $\mathrm{t}$ should give a straight line if pseudo-secondorder kinetics are applicable and $\mathrm{q}_{\mathrm{e}}, \mathrm{k}_{2}$ and $\mathrm{kq}_{\mathrm{e}}{ }^{2}\left(\mathrm{mg} \mathrm{g}^{-1} \mathrm{~min}^{-1}\right)$ can be determined from the slope and intercept of the plot, respectively where $\mathrm{q}_{\mathrm{e}}=1 /$ slope and $\mathrm{k}_{2}=(\text { slope })^{2} /$ Intercept. From Table 2 Validity the data of pseudo first-order model could be investigated by analyzing where the $\mathrm{q}_{\mathrm{e}, \text { cal }}$ values show increasing trends $\left(111.43,59.06\right.$ and $\left.80.18 \mu \mathrm{g} \mathrm{g}^{-1}\right)$ for $\mathrm{Zn}(\mathrm{II}), \mathrm{Cu}(\mathrm{II})$ and $\mathrm{Mn}(\mathrm{II})$ respectively with correlation coefficients $\left(\mathrm{R}^{\wedge} 2\right)$ 0.84-0.977 and higher values of chi-square tests $\mathrm{X}^{\wedge} 2$ [36]. Comparing the experimental $\mathrm{q}_{\mathrm{e}}$ values, a large difference was observed which proves the pseudo first order model is inconvenient for an interpretation of the adsorption kinetics data.

Validity the data of pseudo second-order model could be investigated by analyzing where $\mathrm{q}_{\text {ecal }}$ values show increasing trends (126.58, 113.63 and $121.95 \mu \mathrm{g} \mathrm{g}^{-1}$ ) for $\mathrm{Zn}(\mathrm{II}), \mathrm{Cu}(\mathrm{II})$ and $\mathrm{Mn}$ (II) respectively with correlation coefficients $\left(R^{\wedge} 2\right)$ 0.988-0.992 and lower values of chi-square tests $X^{\wedge} 2$ [36]. Furthermore, the calculated $q_{e}$ values from these second-order model were very close to experimental $\mathrm{q}_{\mathrm{e}}$ values. In the case of the pseudo-first-order model, the calculated $\mathrm{q}_{e}$ values differed severely from the experimental $\mathrm{q}_{e}$ values.

Intra-particle diffusion model: The rate determine step of the reaction between the adsorbate and adsorbent was detected by the hypothesis of the intra-particle diffusion was investigated applying the Morris-Weber equation 5 [37].

$$
q_{t}=k_{d} t^{0.5}+I
$$

where the intra-particle diffusion rate constant $\mathrm{kid}\left(\mu \mathrm{g} \mathrm{g} \mathrm{gin}^{-1 / 2}\right)$ was computed from the slope in the plot of $\mathrm{q}_{\mathrm{t}}$ values versus the squareroot of shaking time and intercept (I) represented contacted layer thickness. the plots $\left(q_{t}\right.$ vs. $\left.t^{1 / 2}\right)$ represent multi-linearity, which indicates two or more steps occurring in the adsorption process. The relationship between $q_{t}$ vs. $t^{1 / 2}$ is the linear realation. The intra-particle diffusion constant was calculated using linear equation (Table 2).

\section{Determination of isotherm adsorption model}

Langmuir and Freundlich model interpreted the data of sorption

\begin{tabular}{|c|c|c|c|c|c|c|c|c|c|c|c|}
\hline \multirow[t]{2}{*}{ Metal ions } & \multirow{2}{*}{$\begin{array}{c}q_{e}(\exp ) \\
\mu g g^{-1}\end{array}$} & \multicolumn{4}{|c|}{ Pseudo first-order } & \multicolumn{4}{|c|}{ Second order Second } & \multicolumn{2}{|c|}{ Intraparticle diffusion } \\
\hline & & $\underset{\left(\mu g g^{-1}\right)}{q_{e}}$ & $\begin{array}{c}k_{1} \\
\left(\mathrm{~min}^{-1}\right)\end{array}$ & $\mathbf{R}^{2}$ & $\begin{array}{c}\text { chi-square tests } \\
\mathrm{X}^{2}\end{array}$ & $\underset{\left(\mu g_{e} g^{-1}\right)}{q_{e}}$ & $\begin{array}{c}\mathbf{k}_{2} \\
\left(\mathbf{g} \mathbf{~ g}^{-1}\right. \\
\left.\mathbf{m i n}^{-1}\right)\end{array}$ & $\mathbf{R}^{2}$ & $\begin{array}{c}\text { chi-square tests } \\
\mathrm{X}^{2}\end{array}$ & $\begin{array}{c}\text { kid, } 1 \\
\left(\mu \mathrm{g} \mathrm{g}^{-1} \min ^{0.5}\right)\end{array}$ & $\begin{array}{c}\text { kid, } 2 \\
\left(\mu \mathrm{g} \mathrm{g}^{-1} \min ^{0.5}\right)\end{array}$ \\
\hline $\mathrm{Zn}$ & 100 & 111.43 & 0.15577 & 0.8450 & 1.17 & 126.58 & 0.0011 & 0.9883 & 5.58 & 21.88 & 2.27 \\
\hline $\mathrm{Cu}$ & 100 & 59.06 & 0.08224 & 0.9778 & 28.38 & 113.64 & 0.0017 & 0.9898 & 1.64 & 11.93 & 6.63 \\
\hline $\mathrm{Mn}$ & 100 & 80.18 & 0.1269 & 0.8359 & 4.90 & 121.95 & 0.0014 & 0.9920 & 3.95 & 20.09 & 3.03 \\
\hline
\end{tabular}
equilibrium. All the isotherm model discussed in detail as follows $[38,39]$ :

Table 2: Adsorption kinetic data obtained from pseudo-first order and pseudo-second-order models at $25^{\circ} \mathrm{C}$.
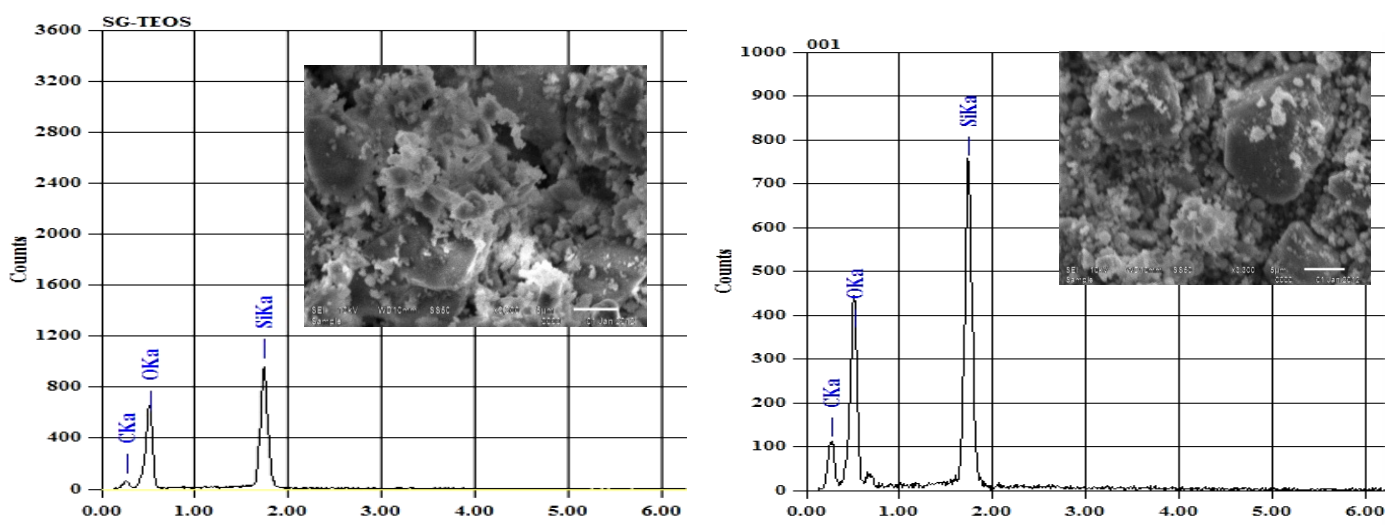

Figure 4: SEM images and EDAX anlysis of the a) silica matrix and b) Nano-HP silica. 
Citation: Bakeir E, Attaf S, El-shahat M (2017) Nano-Silica Modified by Hematoporphyrin for Determination Some of Traces Metals lons (Cu(II), Zn(II) and $\mathrm{Mn}(\mathrm{II})$ ) in Environmental and Pharmaceutical Formula. J Environ Anal Toxicol 7: 495. doi: 10.4172/2161-0525.1000495

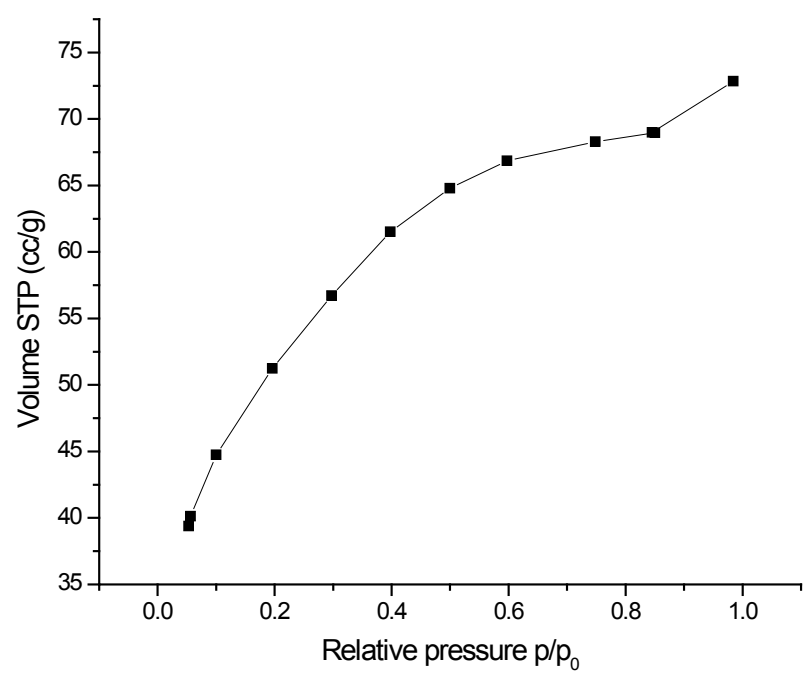

Figure 5: Adsorption isotherms for $\mathrm{N}_{2}$ gas on nano-HP silica sorbent at $520 \mathrm{~K}$.

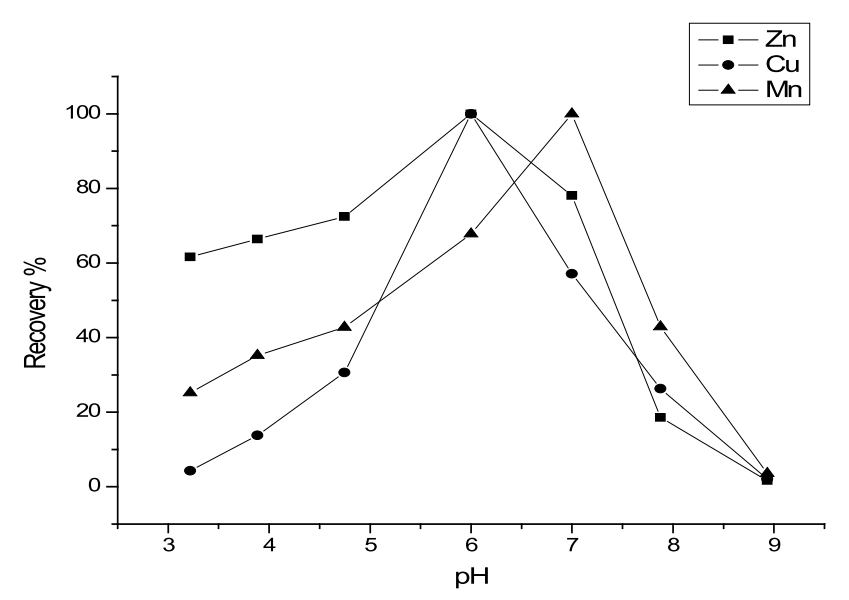

Figure 6: Influence of sample $\mathrm{pH}$ on the recovery of metal ions on $0.1 \mathrm{~g}$ nano-HP silica.

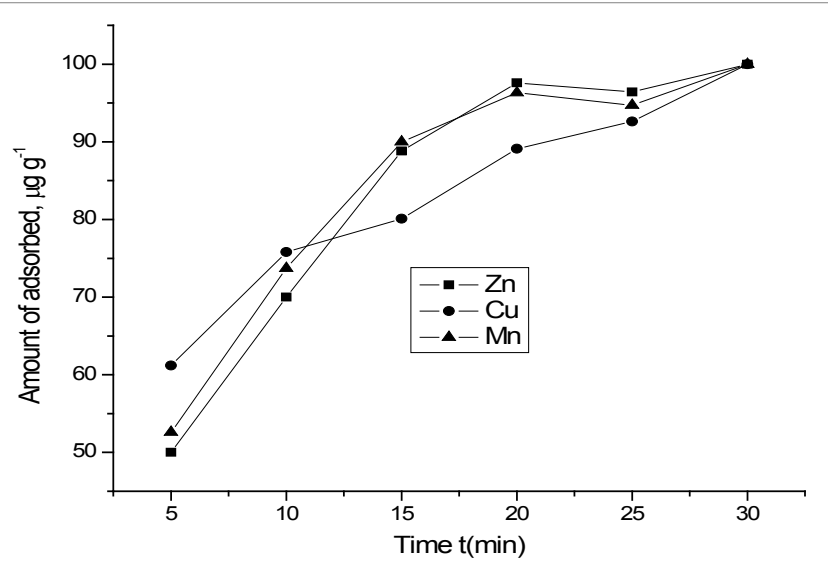

Figure 7: Effect of shaking time on adsorption of metal ions by nano-HP silica: metal ion concentration $0.5 \mu \mathrm{g} \mathrm{mL}^{-1}$, sample volume $(10 \mathrm{~mL})$ and $\mathrm{pH}=6.8 \pm 0.4$, weight of sorbent $0.1 \mathrm{~g}$ and temperature $25^{\circ} \mathrm{C}$.

The Langmuir model is assumed that monolayer of adsorbate molecules filled the surface of adsorbent with at maximum adsorption without any penetration for surface plane and the energy of adsorption is constant. The nonlinear and linear of Langmuir isotherm are given by:

Nonlinear equation

$$
q_{e}=\frac{\left(q_{m} K_{L} C_{e}\right)}{\left(1+K_{L} C_{e}\right)}
$$

Linear equation

$\frac{1}{q_{e}}=\frac{1}{q_{m}}+\frac{1}{K_{L} q_{m}} * \frac{1}{C_{e}}$

where $\mathrm{q}_{e}$ and $\mathrm{K}_{\mathrm{L}}$ are Langmuir constants representing the maximum adsorption capacity for the solid phase loading and the energy constant related to the heat of adsorption, respectively. It can be seen from Table 3 that the isotherm data fits the Langmuir equation well $\left(\mathrm{R}^{2}=0.975-0.998\right)$. The values of $\mathrm{q}_{\mathrm{m}}$ and $\mathrm{K}_{\mathrm{L}}$ for $\mathrm{Zn}(\mathrm{II}), \mathrm{Cu}(\mathrm{II})$ and $\mathrm{Mn}$ (II) were determined from the Figure and were found to be 178.57 , 116.28 and $666.7 \mathrm{mg} / \mathrm{g}$ and $0.7616,0.8032$ and $1.0162 / \mathrm{mg}$, respectively. The Freundlich isotherm model is an empirical relationship describing the adsorption of solutes from a liquid to a solid surface and assumes that different sites with several adsorption energies are involved. The Freundlich adsorption isotherm is the relationship between the amounts of lead adsorbed per unit mass of adsorbent $\left(\mathrm{q}_{\mathrm{e}}\right)$ and the concentration of the lead at equilibrium $\left(\mathrm{C}_{\mathrm{e}}\right)$.

$$
q_{e}=K_{f} C_{e} * \frac{1}{n}
$$

The logarithmic form of the equation becomes,

$$
\log q_{e}=\log K_{f}+\frac{1}{n} * \log C_{e}
$$

where $\mathrm{K}_{\mathrm{f}}$ and $\mathrm{n}$ are the Freundlich constants characteristic of the system. $\mathrm{K}_{\mathrm{f}}$ and $\mathrm{n}$ are the indicator of the adsorption capacity and adsorption intensity, respectively. The ability of the Freundlich model to fit the experimental data was examined. For this case, the plot of log Ce vs $\log$ qe was employed to obtain from the intercept the value of $\mathrm{K}_{\mathrm{f}}$ and from the slope that of n. From Table 3, the Freundlich constants $\mathrm{K}_{\mathrm{f}}$ and $\mathrm{n}$ for $\mathrm{Zn}(\mathrm{II}), \mathrm{Cu}(\mathrm{II})$ and $\mathrm{Mn}(\mathrm{II})$ were found to be $2.48,2.76$ and $3.00 \mathrm{mg} / \mathrm{g}$ and $0.79,0.87$ and 0.91 respectively. The isotherm data fit the Freundlich model well $\left(\mathrm{R}^{2}=0.987,0.976\right.$ and 0.992$)$. Comparison of the obtained isothermal data is depicted in Table 3. The Langmiur and Freundlich regression coefficients proved that the correlation coefficients were stronger with respect to Langmuir model than the Freundlich model. Therefore, adsorption of the studied metal ions from aqueous solution onto Nano HP silica is matted well to the Langmuir isotherm model according to the $\mathrm{R}$ values. The maximum adsorption capacity obtained from the Langmuir isotherm was in agreement with the experimental values.

\section{Sample flow rate}

Sample flow rate is a measure of the contact time between the metal ion in the liquid phase and the solid sorbent. The lower the flow rates

\begin{tabular}{|c|c|c|c|c|c|c|c|}
\hline & \multirow{2}{*}{ Metal ions } & \multicolumn{3}{|c|}{ Langmuir parameters } & \multicolumn{3}{|c|}{ Freundlich parameters } \\
\hline & & \multicolumn{3}{|c|}{$\mathrm{q}_{\max }(\mu \mathrm{g} / \mathrm{g}) \mathrm{KL} \mathrm{R}^{2}$} & $\mathrm{n}$ & $\mathrm{kf}(\mathrm{L} / \mathrm{g})$ & $\overline{\mathrm{R}^{2}}$ \\
\hline Nano HP silica & $\begin{array}{l}\mathrm{Zn} \text { (II) } \\
\mathrm{Cu} \text { (II) } \\
\mathrm{Mn} \text { (II) }\end{array}$ & $\begin{array}{l}178 \\
116 \\
666\end{array}$ & $\begin{array}{l}0.761 \\
0.803 \\
1.016\end{array}$ & $\begin{array}{l}0.998 \\
0.975 \\
0.992\end{array}$ & \begin{tabular}{|l}
0.78 \\
0.86 \\
0.90
\end{tabular} & $\begin{array}{l}2.48 \\
2.76 \\
3.00\end{array}$ & $\begin{array}{l}0.987 \\
0.976 \\
0.992\end{array}$ \\
\hline
\end{tabular}
the longer the contact time and the larger the extent of metal binding. A vacuum pump was connected to the end of the syringe tap to adjust

Table 3: Langmiur and Freundlich isotherm constants for adsotption of metal ions on nano-HP silica at $25^{\circ} \mathrm{C}$. 
Citation: Bakeir E, Attaf S, El-shahat M (2017) Nano-Silica Modified by Hematoporphyrin for Determination Some of Traces Metals lons (Cu(II), Zn(II) and $\mathrm{Mn}(\mathrm{II}))$ in Environmental and Pharmaceutical Formula. J Environ Anal Toxicol 7: 495. doi: 10.4172/2161-0525.1000495

the flow rate. An aliquot of $5 \mathrm{~mL}$ of concentration $0.5 \mu \mathrm{g} \mathrm{mL}^{-1}$ from individual metal ion was adjusted at $\mathrm{pH}$ 6-7 and introduced into the syringe at varying rates from 0.25 to $4.0 \mathrm{~mL} \mathrm{~min}$. Good results showed for $\mathrm{Zn}$ rather than other elements. At flow rate variations in the range from 0.25 to $2.0 \mathrm{ml} \mathrm{min}^{-1}$, the recovery was approximately constant and quantitative. At flow rates higher than $2.0 \mathrm{~mL} \mathrm{~min}^{-1}$, the recovery decreased very slowly. For achievement of a good precision, the flow rate was set at $1.0 \mathrm{~mL} \mathrm{~min}^{-1}$ in subsequent experiments. However,

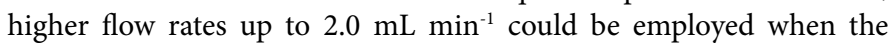
sample concentration is too low to benefit from the decrease in analysis time but at the expense of efficiency.

\section{Desorption metal ions}

Eluent type can influence the lifetime of sorbent and efficiency of the method. The use of complexing agents like thiourea or EDTA was excluded since it might be sorbed by the Nano-HP silica, thus causing chemical changes in the nature of its surface leading to irreproducible recovery data. Hydrochloric and nitric acids are presumed to be the most suitable for desorption of the bound metal ions. The most frequently used is nitric acid because it is suitable with its non-oxidative effect. Universally, dilute mineral acids were found effective for removal of metal ions from Nano-HP silica based sorbents [40]. However, at too low acid concentration the amount of protons may be not enough to protonate the chelation site and to make exchange with the retained metal ion. High acid concentration is not recommended for desorption due to increasing the volume of eluate by neutralization prior to FAAS determination that would reduce the preconcentration factor or contamination from acid. Therefore, concentration of nitric acid was carefully optimized. For this purpose, the metal ions were eluted from the column with $10 \mathrm{~mL}$ of $\mathrm{HNO}_{3}$ solution at varying concentration between $0.1-0.5 \mathrm{~mol} \mathrm{~L}^{-1}$ with $1.0 \mathrm{~mL} \mathrm{~min}^{-1}$ flow rate. The recovery of $\mathrm{Zn}$, $\mathrm{Cu}$ and $\mathrm{Mn}$, was quantitative in the range $90-100 \%$ within concentration $0.1 \mathrm{~mol} \mathrm{~L}^{-1}$. At acid concentration more than $0.1 \mathrm{~mol} \mathrm{~L}^{-1}$, the recovery decreased which could be due to the synergistic effect caused by $\mathrm{NO}_{3}^{-}$ion. Accordingly, the $0.1 \mathrm{~mol} \mathrm{~L}^{-1}$ concentrations were selected as the optimum eluent concentration in the subsequent experiments to achieve high recovery. The volume of eluent necessary to quantitatively remove these elements from the sorbent was investigated.

\section{Breakthrough curve}

The dynamic capacity of the column was computed by percolating it with a metal ion solution with concentration $0.5 \mu \mathrm{g} \mathrm{mL}^{-1}$ and $\mathrm{pH} 6.8$ \pm 0.4 at a flow rate $1.0 \mathrm{~mL} \mathrm{~min}^{-1}$. Breakthrough curves were obtained by measuring the content of metal ions in $5 \mathrm{~mL}$ collected fractions from the effluent as shown in Figure 8. Evidently, the breakthrough point was found in 20, 15 and $10 \mathrm{~mL}$ for $\mathrm{Zn}, \mathrm{Cu}$ and $\mathrm{Mn}$, respectively. The zero-point sorption was reached after passing of $20 \mathrm{~mL}$ for $\mathrm{Mn}$ and 25 $\mathrm{mL}$ for $\mathrm{Cu}$ and $\mathrm{Zn}$. The steep portions in the curves are of higher slopes, which reflect strong retention of metal ions to the sorbent. The working breakthrough capacity could be calculated by the equation:

where $C_{w}$ is the column working capacity $\left(\mu \mathrm{g} \mathrm{g}^{-1}\right), V_{\mathrm{b}}$ is the collected volume of effluent between the first fraction and the breakthrough point $(\mathrm{mL}), C_{\mathrm{o}}$ is the initial concentration of metal ions, $m$ is the weight of Sorbent $(\mathrm{g})$. The capacity values were found to be $200 \mu \mathrm{gg}$ ${ }^{1}$ for $\mathrm{Mn}(\mathrm{II})$ and $250 \mu \mathrm{gg}^{-1}$ for $\mathrm{Zn}(\mathrm{II})$ and $\mathrm{Cu}(\mathrm{II})$, respectively. This revealed good retention of the element onto the column and predicted good preconcentration capability and low limit of detection. The breakthrough capacity is less than the total capacity determined from the extraction isotherm because the first one is determined under dynamic flow of metal ion solution where the contact time is short. On the other hand, the total capacity is determined under static conditions where enough contact time between the metal ion and the sorbent allows high mass transport to the solid phase.

\section{Interference effect}

The influences of some foreign ions which may interfere with sorption of the studied selements onto Nano-HP Silica were investigated in order to identify the method selected. For this purpose, $10 \mathrm{~mL}$ model solution containing $0.5 \mu \mathrm{g} \mathrm{mL}^{-1} \mathrm{Cu}, \mathrm{Zn}$ or $\mathrm{Mn}$ was mixed with the interfering species and adjusted to optimum $\mathrm{pH}$ and passed through the column at a flow rate $1.0 \mathrm{~mL} \mathrm{~min}^{-1}$. The concentration of examined ions were: $\mathrm{Na}\left(1000 \mathrm{mg} \mathrm{L}^{-1}\right), \mathrm{Ca}(\mathrm{II})\left(500 \mathrm{mg} \mathrm{L}^{-1}\right), \mathrm{Mg}$ (II) (100 $\left.\mathrm{mg} \mathrm{L}^{-1}\right), \mathrm{Fe}$ (IIII) $\left(0.1 \mathrm{mg} \mathrm{L}^{-1}\right), \mathrm{Co}(\mathrm{II})\left(0.5 \mathrm{mg} \mathrm{L}^{-1}\right), \mathrm{Pb}$ (II) $\left(0.01 \mathrm{mg} \mathrm{L}^{-1}\right)$, chloride $\left(1000 \mathrm{mg} \mathrm{L}^{-1}\right)$, sulphate $\left(500 \mathrm{mg} \mathrm{L}^{-1}\right)$, nitrate $\left(1000 \mathrm{mg} \mathrm{L}^{-1}\right)$, and oxalate $\left(700 \mathrm{mg} \mathrm{L}^{-1}\right)$. The obtained results are depicted in Figure 9. Strong interference was found by sulfate and lead on the $\mathrm{Cu}$ and $\mathrm{Zn}$ determinations, respectively. The alkaline and alkaline earth metal ions did not interfere with the extraction. Generally, the majority of the examined foreign ions were found to not interfere, which confirms the adequate selectivity of Nano-HP silica material and feasibility for quantitative determinations in natural samples with relevant accuracy. Furthermore, the added concentrations of foreign ions were higher than those existing in most natural samples which predict the validity of the developed procedure.

\section{Influence of sample volume and preconcentration factor}

The volume of the sample was directly related to the value of the preconcentration factor (PF). The high volume of the sample from which the metal ion can be quantitatively preconcentrated, the greater the value of PF. Therefore, the recovery of $0.5 \mu \mathrm{g}$ of metal ions placed in solutions of varying volumes from 100 to $1000 \mathrm{~mL}$ was determined after desorption by $10 \mathrm{~mL}$ from $0.4 \mathrm{~mol} \mathrm{~L}^{-1} \mathrm{HNO}_{3}$ solution. The obtained results are summarized in Table 4. Quantitative recoveries (93-97\%) were achieved at sample volumes in the range of 100-500 mL. Above $500 \mathrm{~mL}$, the recoveries decreased and were not quantitative which might be attributed to incomplete retention of metal ions, probably by the washing action of the column by the sample itself. Therefore, a sample volume $\leq 500 \mathrm{~mL}$ was recommended for the simultaneous preconcentration of all metal ions in order to ensure good recovery. A preconcentration factor of range 12.4-29.5 was obtained by the ratio of the maximum sample volume to the eluent volume.

\section{Reusability and precision}

Reusability test was studied because it indicates the number of preconcentration cycles in which the column can be used without losing its analytical efficiency. Indeed, the whole experimental work was carried out on the same sorbent plugs either in batch or packed column methodology. There was no need to replace the plugs since it gave quantitative sorption when tested from time to time. Therefore, the reusability could be obtained by counting the total number of preconcentration cycles in which the plugs were used. It was found that the capacity of the sorbent was practically constant after its repeated use more than 70 cycles of preconcentration and desorption. The use

\begin{tabular}{|c|c|c|c|c|c|c|}
\hline Sorbent & Element & $\begin{array}{c}\text { Initial } \\
\text { volume } \\
\text { (ml) }\end{array}$ & $\begin{array}{c}\text { Concentration } \\
\boldsymbol{\mu g} / \mathbf{L}\end{array}$ & $\begin{array}{c}\text { Desorption } \\
\text { Volume (ml) }\end{array}$ & $\begin{array}{c}\text { Recovery } \\
\mathbf{( \% )}\end{array}$ & PF \\
\hline \multirow{2}{*}{$\begin{array}{c}\text { Nano- } \\
\text { HP silica }\end{array}$} & $\mathrm{Zn}(\mathrm{II})$ & 100 & 0.5 & 10 & 95.5 & 29.5 \\
\cline { 2 - 7 } & $\mathrm{Cu}(\mathrm{II})$ & 100 & 0.5 & 10 & 94.7 & 12.4 \\
\cline { 2 - 7 } & $\mathrm{Mn}(\mathrm{II})$ & 100 & 0.5 & 10 & 96.1 & 18.1 \\
\hline
\end{tabular}

Table 4: Preconcentration of metal ions on $0.1 \mathrm{~g}$ nano-HP silica packed on column. 
Citation: Bakeir E, Attaf S, El-shahat M (2017) Nano-Silica Modified by Hematoporphyrin for Determination Some of Traces Metals lons (Cu(II), Zn(II) and $\mathrm{Mn}(\mathrm{II})$ ) in Environmental and Pharmaceutical Formula. J Environ Anal Toxicol 7: 495. doi: 10.4172/2161-0525.1000495

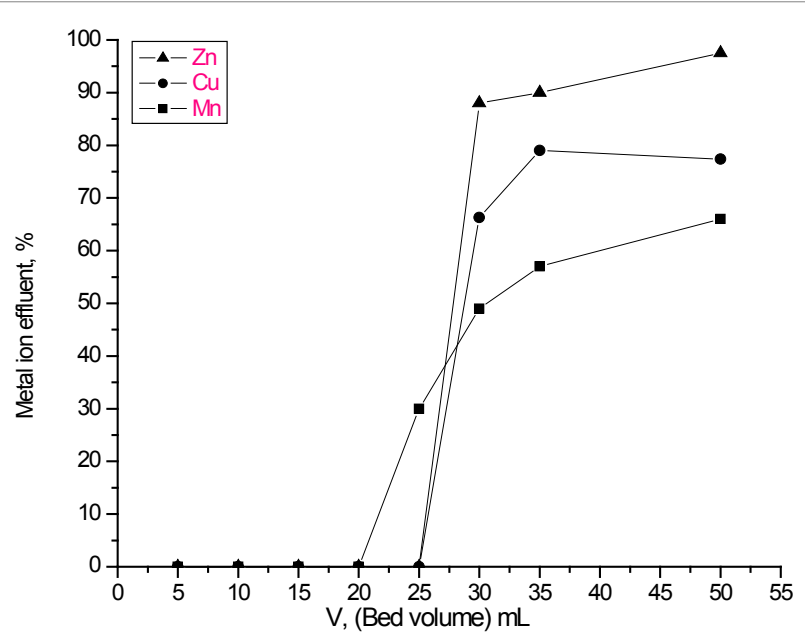

Figure 8: Breakthrough curve of $\mathrm{Zn}(\mathrm{II}), \mathrm{Cu}(\mathrm{II})$ and $\mathrm{Mn}$ (II) $\left(0.5 \mu \mathrm{g} \mathrm{ml}^{-1}\right)$ on

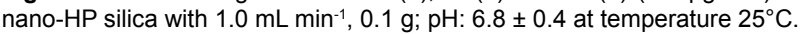

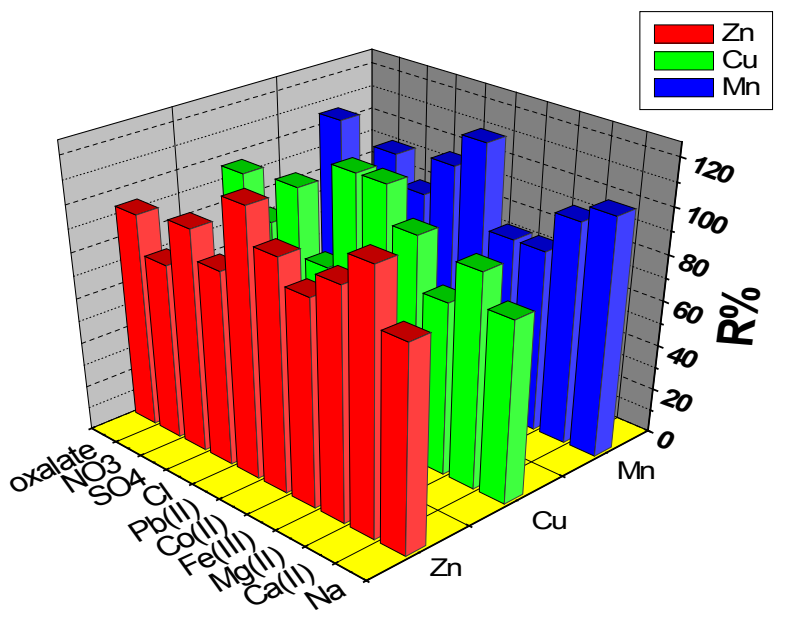

Figure 9: Bar presentation of interference effect by some cations and anions on the recovery of $\mathrm{Zn}(\mathrm{II}), \mathrm{C}(\mathrm{II})$ and $\mathrm{Mn}(\mathrm{II})$.

of low concentration of eluent assisted extending the lifetime of the Sorbent and enabled the multiple use of Sorbent. The precision of the determination of these metal ions was evaluated under the optimum conditions for preconcentration and desorption by column method. Model solution was prepared by dilution of AAS standards to a concentration of $1.0 \mu \mathrm{g} \mathrm{mL} \mathrm{m}^{-1}$ each metal ion. The sample was subjected to preconcentration desorption cycle and the precision was estimated as the relative standard deviation (RSD) for five replicates. Results showed good precision (less than 10\%) with RSD vary in the range 6.2-8.5\%.

\section{Accuracy}

The add-found test was employed to evaluate the accuracy of the developed preconcentration method. Synthetic samples, containing individual metal ion at $0.5 \mu \mathrm{g} \mathrm{mL}^{-1}$ level, were prepared and passed into the column under the optimized conditions then the recovery and relative standard deviation RSD\% values were found. The obtained results are compiled in Table 5. Quantitative recovery was achieved varying between 98.00 and $102.00 \%$ and the corresponding RSD values were in the range $0.20-1.02 \%$. Obviously, the recovery is adequate with most measurements and RSD \% is quite good. The results are in good agreement, showing that the proposed method might be used for metal ion determination, even at low concentrations. Finally, the recovery percentage and RSD\% values are extensively efficient for analytical determination of these elements at low concentrations.

\section{Analytical figures of merit}

The analytical Figures of merit of the present procedure with determination by FAAS were evaluated. Linear calibration graphs have been obtained that could be represented by the regression equations: $\mathrm{A}=0.19+0.104 \mathrm{C} \quad(\mathrm{R}=0.999), \quad \mathrm{A}=-0.0123+0.10125 \mathrm{C} \quad(\mathrm{R}=0.999) \quad$ and $\mathrm{A}=0.016+0.0515 \mathrm{C}(\mathrm{R}=0.997)$ for $\mathrm{Cu}, \mathrm{Zn}$ and $\mathrm{Mn}$, respectively. The analytical range was found to be $0.1-10 \mu \mathrm{g} \mathrm{L}-1$. The detection limit defined as $(3 \sigma)$, where $\sigma$ is the standard deviation of the blank determination, was found to be $0.12,0.01$ and $0.03 \mu \mathrm{g} \mathrm{L}^{-1}$ and the limit of quantification $(10 \sigma)$ was $0.41,0.03$ and $0.12 \mu \mathrm{g} \mathrm{L}^{-1}$, respectively. Obviously, the limit of detections is less than the concentration of the tested metal ions in the majority of real samples which enables quantification of these elements with sufficient accuracy.

\section{Analysis of real samples}

The applicability of the developed sorbent was evaluated by analysis of several real samples. Firstly, the pharmaceutical preparation, Kerovit tablet, was analyzed. The obtained results are shown in Table 6. Adequate recovery values were obtained in the range $90.2-93.3 \%$. The corresponding RSD values varied in the ranges $4.1-8.6 \%$, which are reasonable. Secondly, the content of metal ions under investigation was determined in fish liver, olive leaves and drinking water. The obtained results are summarized in Table 7 . The RSD \% values are found to be in the range 3.7-9.7\% which is considered relevant (less than 10\%) for real samples. The obtained data conferred susceptible accuracy of the

\begin{tabular}{|c|c|c|c|c|}
\hline Metal ion & $\begin{array}{c}\text { Addeda }^{\mathbf{a}}, \\
\mathbf{\mu g ~ m L}^{-\mathbf{1}} \mathbf{( m g )}\end{array}$ & $\begin{array}{c}\text { Found } \\
\mathbf{\mu g ~ m}^{-1}\end{array}$ & Recovery (\%) & RSD (\%) \\
\hline $\mathrm{Zn}(\mathrm{II})$ & 0.5 & 0.51 & 102.00 & 0.98 \\
\hline $\mathrm{Cu}(\mathrm{II})$ & 0.5 & 0.49 & 98.00 & 1.02 \\
\hline $\mathrm{Mn}(\mathrm{II})$ & 0.5 & 0.498 & 99.60 & 0.20 \\
\hline
\end{tabular}

aMean value for five measurements.

Table 5: Accuracy of the Nano-HP silica method calculated by add-found test.

\begin{tabular}{|c|c|c|c|c|}
\hline Metal ion & $\begin{array}{c}\text { Reported } \\
(\mathbf{m g})\end{array}$ & $\begin{array}{c}\text { Found }^{\mathbf{a}} \\
(\mathbf{m g})\end{array}$ & Recovery (\%) & RSD (\%) \\
\hline $\mathrm{Zn}(\mathrm{II})$ & 5.0 & 4.63 & 92.6 & 3.99 \\
\hline $\mathrm{Cu}(\mathrm{II})$ & 1.3 & 1.17 & 90.0 & 5.55 \\
\hline $\mathrm{Mn}(\mathrm{II})$ & 1.3 & 1.21 & 93.0 & 3.71 \\
\hline
\end{tabular}

a Mean value for five measurements

Table 6: Determination of $\mathrm{Cu}, \mathrm{Zn}$ and $\mathrm{Mn}$ in the pharmaceutical sample Kerovit.

\begin{tabular}{|c|c|c|c|}
\hline \multirow{2}{*}{ Sample analyzed } & Metal ion & \multicolumn{2}{|c|}{} \\
\cline { 3 - 4 } & & Found $(\boldsymbol{\mu g} / \mathbf{L})^{*}$ & \multicolumn{2}{|c|}{ RSD\% } \\
\hline \multirow{3}{*}{ Fish liver } & $\mathrm{Cu}(\mathrm{II})$ & $0.045 \pm 0.004$ & 8.88 \\
& $\mathrm{Zn}(\mathrm{II})$ & $0.087 \pm 0.003$ & 3.44 \\
& $\mathrm{Mn}(\mathrm{II})$ & $0.064 \pm 0.006$ & 9.37 \\
& & & \\
Olive leaves & $\mathrm{Cu}(\mathrm{II})$ & $0.073 \pm 0.005$ & 6.84 \\
& $\mathrm{Zn}(\mathrm{II})$ & $0.395 \pm 0.016$ & 4.05 \\
& $\mathrm{Mn}(\mathrm{II})$ & $0.075 \pm 0.002$ & 2.66 \\
Drinking water & $\mathrm{Cu}(\mathrm{II})$ & $0.034 \pm 0.002$ & 5.88 \\
& $\mathrm{Zn}(\mathrm{II})$ & $0.233 \pm 0.022$ & 9.44 \\
& $\mathrm{Mn}(\mathrm{II})$ & $0.059 \pm 0.002$ & 3.38 \\
\hline
\end{tabular}

*Mean value of five replicate measurements $(n=5)$

Table 7: Determination of metal ions in environmental samples by the developed procedure by Nano-HP silica. 
Citation: Bakeir E, Attaf S, El-shahat M (2017) Nano-Silica Modified by Hematoporphyrin for Determination Some of Traces Metals lons (Cu(II), Zn(II) and $\mathrm{Mn}(\mathrm{II}))$ in Environmental and Pharmaceutical Formula. J Environ Anal Toxicol 7: 495. doi: 10.4172/2161-0525.1000495

Page 8 of 9

developed method based on the satisfactory values of RSD, in addition to the reasonably high sensitivity and validity of the proposed method, for determination in pharmaceutical and environmental samples.

\section{Conclusion}

Nano-sorbent prepared by simple and fast fabrication solgel method. The prepared sorbent was characterized by various microscopic and spectroscopic tools. It showed fast equilibration with the studied elements and easy regeneration. Novel sorbent was in a size of $7.4 \mathrm{~nm}$ of spherical shape. Hematoporphyrin was bonded from- $\mathrm{COOH}$ and-OH groups to surface of silica at-Si-O$\mathrm{Si}$ and $-\mathrm{OH}$. A good a preconcentration factor was achieved. The developed methods have been successfully applied for determination of metal ions in pharmaceutical and environmental samples. Nano-HP silica is highly selective for determination of $\mathrm{Zn}$ (II) rather than $\mathrm{Cu}$ (II) and $\mathrm{Mn}(\mathrm{II})$. Nano-HP silica was considered a perfect solid phase extraction with a good limit of detection and longer line arrange of concentration metal ions. This made the proposed procedure alternative to other reported solid phase extraction methods for application in pharmaceutical and environmental samples.

\section{References}

1. Sharma S, Rana S, Thakkar A, Baldi A, Murthy RS, et al. (2016) Physical, Chemical and Phytoremediation Technique for Removal of Heavy Metals. Journal of Heavy Metal Toxicity and Diseases.

2. Özcan M, Akman S, Özeroğlu C (2002) The use of water soluble polymers for the pre-concentration and separation of copper, lead, and chromium prior to their determination by graphite furnace atomic absorption spectrometry. Analytical letters 35: 1075-1083.

3. Garcia-Falcón MS, Cancho-Grande B, Simal-Gándara J (2004) Stirring bar sorptive extraction in the determination of PAHs in drinking waters. Water research 38: 1679-1684.

4. Ghaedi M, Asadpour E, Vafaie A (2006) Simultaneous preconcentration and determination of copper, nickel, cobalt, lead, and iron content using a surfactantcoated alumina. Bulletin of the Chemical Society of Japan 79: 432-436.

5. Song EJ (2003) Determination of Trace Heavy Metal ions in Water by FAAS after Preconcentration with ASTO. InAdvanced Materials Research 826: 267-270.

6. Dahaghin Z, Mousavi HZ, Sajjadi SM (2017) Synthesis and Application of Magnetic Graphene Oxide Modified with 8-Hydroxyquinoline for Extraction and Preconcentration of Trace Heavy Metal lons. ChemistrySelect 2: 1282-1289.

7. Mehdinia A (2014) Preconcentration and determination of organochlorine pesticides in seawater samples using polyaniline/polypyrrole-cellulose nanocomposite-based solid phase extraction and gas chromatography-electron capture detection. Journal of the Brazilian Chemical Society 25: 2048-2053.

8. Jamhour R (2016) The Solid Phase Extraction of Some Heavy Metal lons Using Dodecylamine Pillared Mg-Al Layered Double Hydroxides. American Chemical Science Journal 15: 1-10.

9. Marenna E (2008) Sol-gel synthesis of functional nanocomposites based on inorganic oxides (Doctoral dissertation, Università degli Studi di Napoli Federico II) p: 52-53.

10. Zendelovska D, Pavlovska G, Cundeva K, Stafilov T (2001) Electrothermal atomic absorption spectrometric determination of cobalt, copper, lead and nickel traces in aragonite following flotation and extraction separation. Talanta 54: 139-46.

11. Kajiyama T, Sakai S, Inoue J, Yoshino T, Ohmuro S, et al. (2016) Synthesis of a Metal Ion Adsorbent from Banana Fibers and Its Adsorption Properties for Rare Metal Ions. Journal of Ion Exchange 27: 57-62.

12. Maeki M, Hatanaka Y, Yamashita K, Miyazaki M, Ohto K (2014) Solvent Extraction Behavior of Metal lons with Calixarene Derivatives by Using a Microreactor. Solvent Extraction Research and Development, Japan 21: 77-82.

13. Pereira AS, Ferreira G, Caetano L, Martines MA, Padilha PM, et al. (2010) Preconcentration and determination of $\mathrm{Cu}$ (II) in a fresh water sample using modified silica gel as a solid-phase extraction adsorbent. Journal of hazardous materials 175: 399-403.
14. Thavasi V, Singh G, Ramakrishna S (2008) Electrospun nanofibers in energy and environmental applications. Energy \& Environmental Science 1: 205-221.

15. Tian M, Yan H, Row KH (2009) Solid-phase extraction of tanshinones from Salvia Miltiorrhiza Bunge using ionic liquid-modified silica sorbents. Journal of Chromatography B 877: 738-742.

16. Zidan WI, Abo-Aly MM, Elhefnawy OA, Bakier E (2015) Batch and column studies on uranium adsorption by Amberlite XAD-4 modified with nanomanganese dioxide. Journal of Radioanalytical and Nuclear Chemistry 304: 645-653.

17. Furusawa N (2005) Determination of DDT in animal fats after matrix solidphase dispersion extraction using an activated carbon filter. Chromatographia 62: 315-318.

18. Oliveira RV, Lemos VA (2012) Synthesis of a New Sorbent Based on Grafted PUF for the Application in the Solid Phase Extraction of Cadmium and Lead. InPolyurethane.

19. Pacheco PH, Smichowski P, Polla G, Martinez LD (2009) Solid phase extraction of Co ions using L-tyrosine immobilized on multiwall carbon nanotubes. Talanta 79: 249-253.

20. Camel V (2003) Solid-phase extraction. Compr Anal Chem 41: 393-457

21. Goswami A, Singh AK (2002) 1, 8-Dihydroxyanthraquinone anchored on silica gel: synthesis and application as solid phase extractant for lead (II), zinc (II) and cadmium (II) prior to their determination by flame atomic absorption spectrometry. Talanta 2002 58: 669-678.

22. Reger DL, Smith DM, Shimizu KD, Smith MD (2004) Syntheses and solid state structures of europium and terbium complexes of $\mathrm{N}, \mathrm{N}^{\prime}$-bis (2-pyridylmethyl) urea and N, N'-bis (3-pyridylmethyl) oxalamide. Polyhedron 23: 711-717.

23. Cui Y, Chang X, Zhu X, Luo H, Hu Z, et al. (2007) Chemically modified silica gel with $p$-dimethylaminobenzaldehyde for selective solid-phase extraction and preconcentration of $\mathrm{Cr}$ (III), $\mathrm{Cu}$ (II), Ni (II), Pb (II) and Zn (II) by ICP-OES. Microchemical Journal 87: 20-26.

24. Marenna E (2008) Sol-gel synthesis of functional nanocomposites based on inorganic oxides (Doctoral dissertation, Università degli Studi di Napoli Federico II).

25. Wei TY, Chang TF, Lu SY, Chang YC (2007) Preparation of monolithic silica aerogel of low thermal conductivity by ambient pressure drying. Journal of the American Ceramic Society 90: 2003-2007.

26. Sardar S, Sarkar S, Myint MT, Al-Harthi S, Dutta J, et al. (2013) Role of central metal ions in hematoporphyrin-functionalized titania in solar energy conversion dynamics. Physical Chemistry Chemical Physics 15: 18562-18570.

27. Sadek OM, Reda SM, Al-Bilali RK (2013) Preparation and characterization of silica and clay-silica core-shell nanoparticles using sol-gel method. Adv in Nanopart 2: 165-175.

28. Lin J, Dan H, Ding $Y$ (2012) Synthesis of High-purity Spherical Silica Nanoparticles from Powder Quartz by Improved Sol-Gel Method. Chemistry Letters 41: 943-944.

29. Wang X, Guo Y, Yang L, Han M, Zhao J, et al. (2012) Nanomaterials as sorbents to remove heavy metal ions in wastewater treatment. J Environ Anal Toxicol 2: 1000154.

30. Llewellyn PL, Bloch E, Bourrelly S (2012) Surface area/porosity, adsorption, diffusion. Characterization of Solid Materials and Heterogeneous Catalysts: From Structure to Surface Reactivity 2: 853-879.

31. Javadian H, Koutenaei BB, Shekarian E, Sorkhrodi FZ, Khatti R, et al. (2014) Application of functionalized nano HMS type mesoporous silica with $\mathrm{N}$-(2aminoethyl)-3-aminopropyl methyldimethoxysilane as a suitable adsorbent for removal of $\mathrm{Pb}$ (II) from aqueous media and industrial wastewater. Journal of Saudi Chemical Society.

32. Shokrollahi A, Montazerozohori M, Mehrpour T, Tavallali H, Khafri BZ, et al. (2013) Sodium dodecyl sulfate coated y-alumina support modified by a new Schiff base for solid phase extraction and flame-AAS determination of lead and copper ions. Química Nova 36: 1354-1359.

33. Miller JW (1986) Adsorption Technology: A Step-by-Step Approach to Process Evaluation and Application. Journal of Environment Quality 15: 94.

34. Yuh-Shan H (2004) Citation review of Lagergren kinetic rate equation on adsorption reactions. Scientometrics 59: 171-177. 
Citation: Bakeir E, Attaf S, El-shahat M (2017) Nano-Silica Modified by Hematoporphyrin for Determination Some of Traces Metals lons (Cu(II), Zn(II) and $\mathrm{Mn}(\mathrm{II}))$ in Environmental and Pharmaceutical Formula. J Environ Anal Toxicol 7: 495. doi: 10.4172/2161-0525.1000495

35. Ho YS, McKay G (1999) Pseudo-second order model for sorption processes. Process biochemistry 34: 451-465.

36. Chowdhury S, Das Saha $P$ (2011) Comparative analysis of linear and nonlinear methods of estimating the pseudo-second-order kinetic parameters for sorption of malachite green onto pretreated rice husk. Bioremediation journal 15: 181-188.

37. Weber WJ, Morris JC (1963) Kinetics of adsorption on carbon from solution Journal of the Sanitary Engineering Division 89: 31-60.
38. Langmuir I (1918) The adsorption of gases on plane surfaces of glass, mica and platinum. Journal of the American Chemical society 40: 1361-1403.

39. Freundlich H, Hatfield HS (1926) Colloid \& capillary chemistry. London: Metheun.

40. Buke B, Divrikli U, Soylak M, Elci L (2009) On-line preconcentration of copper as its pyrocatechol violet complex on Chromosorb 105 for flame atomic absorption spectrometric determinations. Journal of hazardous materials 163: 1298-1302. 